\title{
Multicultural and Colorblind Ideology, Stereotypes, and Ethnocentrism among Black and White Americans
}

\author{
Carey S. Ryan \\ University of Nebraska at Omaha \\ Jennifer S. Hunt \\ University of Nebraska - Lincoln \\ Joshua A. Weible, Charles R. Peterson and Juan F. Casas \\ University of Nebraska at Omaha
}

\begin{abstract}
We examined Blacks' and Whites' perceptions of group variability and positivity as well as their beliefs about the extent to which multiculturalism and colorblindness would improve intergroup relations. In two studies, responses to questionnaires indicated that the tendency to endorse multiculturalism more than colorblindness was greater among Blacks than Whites; Blacks consistently endorsed multiculturalism more than colorblindness and Whites endorsed colorblindness more than did Blacks. Both studies also revealed evidence of outgroup homogeneity and ethnocentrism. Stronger endorsement of multiculturalism relative to colorblindness predicted stronger stereotypes among Blacks, whereas stronger endorsement of colorblindness relative to multiculturalism predicted stronger stereotypes among Whites. In Study 2, stronger endorsement of multiculturalism relative to colorblindness predicted less ethnocentrism; this relationship did not depend on ethnicity.
\end{abstract}

KEYWORDS ethnocentrism, intergroup relations, multiculturalism, out-group homogeneity, stereotypes

Although largely motivated by the desire to improve relations between ethnic groups in the US, especially between Blacks and Whites, stereotyping research has primarily focused on Whites' stereotypes of and prejudice toward ethnic minorities. An assumption underlying much of this work is that perceiving differences between ethnic groups is problematic (Lee, Jussim, \& McCauley, 1995; Ryan, 2002; Wolsko, Park, Judd, \& Wittenbrink, 2000). Recent work, however, suggests that a multicultural ideology in which group differences are acknowledged may have more positive consequences for ethnic

\footnotetext{
$\overline{\text { Author's note }}$

Address correspondence to Carey S. Ryan, Department of Psychology, University of Nebraska at Omaha, Omaha, NE, 68182-0274, USA.

[email: careyryan@mail.unomaha.edu]
} 
minorities (Caughy, O'Campo, Randolph, \& Nickerson, 2002) and for intergroup relations more generally (Berry \& Kalin, 1995; Park \& Judd, 2005; Richeson \& Nussbaum, 2004).

The purpose of the research presented in this article was twofold. First, we wished to examine whether Black and White Americans differ in the degree to which they endorse colorblind and multicultural approaches to improving intergroup relations. Second, we wondered whether beliefs about the potential for multiculturalism versus colorblindness to improve intergroup relations would predict stereotype strength and (weaker) ethnocentrism as has been suggested in recent work (Judd, Park, Ryan, Brauer, \& Kraus, 1995; Park \& Judd, 2005; Richeson \& Nussbaum, 2004; Verkuyten, 2005; Wolsko et al., 2000).

\section{Multicultural versus colorblind ideology}

Colorblind and multicultural ideologies are perhaps the most prominent interethnic ideologies currently. Indeed, the colorblind ideology has dominated public debate in the US, developing in the wake of the 1960s Civil Rights Movement during which blatant racism and discrimination by Whites against Blacks was the focus of public attention (Barrett \& George, 2005). Efforts to promote a colorblind ideology in which all people were to be judged as individual human beings-without regard to race or ethnicity—-were intended to eradicate racism and discrimination, promote justice, and generally improve the economic and social climate for Blacks in the US. Presumably, a colorblind ideology would thus also promote harmony between ethnic groups. According to this colorblind ideology, then, race and ethnic distinctions can and should be ignored and people should be treated in an identical manner.

The multicultural ideology has recently begun to attain greater prominence in the US, primarily as a result of greater demographic diversity, a growing realization that people may be incapable of simply ignoring some differences, for example, obvious differences in physical features (Ito \& Urland, 2003; Norton, Sommers,
Apfelbaum, Pura, \& Ariely, 2006), and concerns about a colorblind ideology that has become so strong that minority groups' unique histories, values, and experiences are often ignored (Barrett \& George, 2005; Schofield, 2001). The multicultural ideology is generally characterized by a belief that differences among racial and ethnic groups should be recognized and appreciated. Rather than ignore group membership, then, adherents of multiculturalism believe that people should seek to understand, accept, and even embrace ethnic differences as a means of promoting justice, including better economic and social conditions for ethnic minorities, and intergroup harmony.

Some research suggests that Blacks and Whites may differ in their endorsement of colorblind and multicultural ideologies. Cross-cultural psychologists (Berry, 1999; Berry \& Kalin, 1995), for example, have examined multiculturalism and the acculturation of immigrants, contrasting multiculturalism with assimilation. Assimilation refers to the belief that the members of immigrant groups should conform to mainstream society, whereas colorblindness refers to the belief that people should ignore ethnic group membership in judgments of individuals. Thus, although assimilation may be associated with colorblindness (Markus, Steele, \& Steele, 2002), the two ideologies are conceptually distinct. In any case, cross-cultural research indicates that the members of immigrant and other non-dominant groups tend to endorse multiculturalism, whereas dominant group members tend to endorse assimilation (cf. Verkuyten, 2005).

Intergroup relations research also suggests that Whites and Blacks may differ in the extent to which they endorse colorblind and multicultural ideologies for improving intergroup relations. Judd et al. (1995), for example, argued that White youth are socialized to believe that ethnic minorities are no different from the majority White population and that making distinctions based on skin color is wrong. That is, White youth are taught to endorse a colorblind ideology (Schofield, 2001), attempting to see everyone as equal and as individuals rather than as members of a particular ethnic group. 
In contrast, Blacks in the US have a history of oppression and discrimination, which is believed to have influenced their beliefs about the importance of ethnicity as well as their strategies for promoting survival and well-being (Harrison, Wilson, Pine, Chan, \& Buriel, 1990; Judd et al., 1995; Markus et al., 2002; Sellers \& Shelton, 2003). Black families, for example, have developed socialization strategies to help their children learn to function in both mainstream and Black society. These racial socialization strategies include messages that are designed to instill ethnic pride and help children understand the role that ethnicity plays in our society (Caughy et al., 2002) and those that convey the importance of recognizing and overcoming racial barriers

Other research similarly indicates that ethnic group membership is more central to the social identity of ethnic minority (vs. majority) group members (Brewer, 1993; Phinney, 1992; Simon \& Pettigrew, 1990). Indeed, Whites typically have a relatively weak awareness of their racial identity and of the impact that being White has on their social standing, accomplishments, and daily lives (Swim \& Miller, 1999). Ethnic minority group members would thus seem more likely than Whites to adopt an ideology that advocates the recognition and appreciation of the unique customs, traditions, and values of their ethnic in-groups as opposed to a colorblind ideology, which suggests that ethnicity is irrelevant.

The assertion that Whites may endorse a colorblind ideology more strongly than do Blacks does not imply that Whites do not harbor prejudiced beliefs or exhibit discriminatory behaviors. Whites who espouse a colorblind ideology may exhibit bias in subtle ways and/or in situations in which non-race justifications for judgments and behaviors are available (Gaertner \& Dovidio, 1986). Indeed, endorsement of a colorblind ideology may sometimes serve to justify a lack of awareness or unwillingness to address issues of prejudice and discrimination (Barrett \& George, 2005; Flagg, 1993). In other words, believing that differences between ethnic and racial groups can and should be ignored may enable Whites to believe that they are behaving fairly-treating everyone the same-so that action to alleviate inequalities is believed to be unnecessary (Barrett \& George, 2005; Flagg, 1993; Gotanda, 1995; Markus et al., 2002).

\section{Relationship between ideology and group perceptions}

A few studies have examined the effects of multicultural versus colorblind ideology on intergroup perceptions. Wolsko et al. (2000) presented White participants with a message advocating a colorblind or a multicultural ideology for achieving intergroup harmony. They found that although White participants who received the multicultural (vs. colorblind) message exhibited stronger stereotypes and were more likely to use stereotypes in judgments of ethnic out-group members, their judgments tended to more accurate. Whether the multicultural message actually changed participants' stereotypes or freed them to express their existing stereotypes by legitimizing the expression of ethnic group differences is unclear. In any case, multiculturalism was associated with the expression of stronger stereotypes about ethnic out-groups.

Other research indicates that multiculturalism is associated with less bias against ethnic out-groups (Park \& Judd, 2005; Verkuyten, 2005). Richeson and Nussbaum (2004), for example, presented White participants with the same colorblind and multicultural messages used by Wolsko et al. (2000). Richeson and Nussbaum found that participants who had been randomly assigned to receive the colorblind message exhibited greater implicit and explicit ethnocentrism than did those exposed to the multicultural message.

Overall, then, existing research indicates that messages advocating multiculturalism result in both stronger stereotypes and less ethnocentrism than do messages advocating colorblindness. However, the research examining multicultural and colorblind ideologies and their relationships to stereotypes and ethnocentrism is rather sparse. Few studies have examined these issues among ethnic minority groups and few have assessed participants' personal endorsement of these ideologies as ways of promoting intergroup harmony. Further, to our knowledge, these 
issues have not been examined among Black and White Americans.

Indeed, research examining Blacks' and Whites' in-group and out-group perceptions has been surprisingly limited. Judd et al. (1995) reported three studies examining perceived variability, stereotypicality, and positivity among Black and White college students in Boulder, Colorado. Their results indicated that Blacks exhibited stronger stereotypes, perceiving their in-groups and out-groups to be less variable and more stereotypic than did Whites. Blacks also exhibited ethnocentrism, judging their in-group more positively than the White outgroup, whereas Whites judged the Black outgroup more positively than their own group. Although Judd et al. suggested that these findings may have resulted from differences in intergroup ideologies, they did not directly assess them.

\section{Current research}

Our goals in the present research were to examine multicultural and colorblind ideologies and intergroup perceptions among Black and White Americans. We expected that Blacks would endorse multiculturalism as a way to promote intergroup harmony more strongly than would Whites, whereas Whites would endorse colorblindness as a way to promote intergroup harmony more strongly than would Blacks. We also expected that Blacks would exhibit stronger stereotypes than Whites, as well as outgroup homogeneity and ethnocentrism (Judd et al., 1995). Judd et al., however, found that Whites did not exhibit out-group homogeneity in explicit judgments of Blacks and exhibited ethnocentrism on only one measure-the feeling thermometer task. Indeed, concerns about social desirability and social norms advocating colorblindness have led researchers to devote a great deal of attention to developing measures that attempt to tap Whites 'true' or implicit attitudes toward Blacks and other minority groups (e.g. Fazio, Jackson, \& Dunton, 1995; Judd et al., 1995). But out-group homogeneity and ethnocentrism are also robust effects (Brauer, 2001; Mullen, Brown, \& Smith, 1992). We therefore expected to find evidence of out-group homogeneity and ethnocentrism among Blacks, but were less confident whether these effects would be evident among Whites.

Finally, stronger endorsement of a multicultural relative to a colorblind ideology was expected to be associated with stronger stereotypes (i.e. less perceived group variability and greater perceived group stereotypicality) among Blacks. However, Whites may be reluctant to express stereotypes even when they endorse a multicultural ideology. Indeed, to the extent that a colorblind ideology reflects an unwillingness and/or inability (e.g. because of a lack of awareness, Markus et al., 2002) to deal with prejudice and discrimination (Barrett \& George, 2005; Flagg, 1993; Gotanda, 1995), Whites who more strongly endorse colorblindness (vs. multiculturalism) might even be expected to exhibit stronger stereotypes.

\section{Study 1}

\section{Method}

Participants Twenty Black ( 10 female, 9 male, 1 unknown) and 67 White (34 female, 33 male) participants completed a questionnaire concerning their views about ethnic group relations in the US. Participants ranged in age from 17 to 64 years $(M=33.00, S D=14.28)$. Fifty percent reported their annual income to be less than US $\$ 20,000$ annually; $34.5 \%$ had incomes between US\$20,000 and US\$60,000, and $15.5 \%$ had an income greater than US $\$ 60,000$. Nearly half $(47 \%)$ reported that they had a college degree, $26.7 \%$ had completed some college, and $19.8 \%$ had a high school diploma or the General Education Development (GED) equivalent. Five participants $(5.8 \%)$ had not completed high school. Black and White participants did not significantly differ in age or income, both $p s>$.21. However, Black participants were marginally more highly educated than were White participants $(F(1,84)=3.35, p=.07)$.

All participants were individuals who attended a live forum titled 'Nebraska Connects: Dialogue on Diversity' that aired on the Nebraska Educational Television network. Data for the present study were gathered before 
the program, so there is no possibility that the program influenced participants' responses. However, individuals who choose to attend a forum on diversity may have attitudes and beliefs that differ from the general population. In Study 2, we tested our hypotheses on a more general sample of college students.

Procedure and materials Participants completed an inventory concerning their intergroup attitudes and beliefs. Five variables are relevant to the present study. First, participants used a feeling thermometer to indicate their affective reactions to a number of social groups, including Whites and Blacks. They indicated their feelings about each group on a scale from 0 (very coolly) to 100 (very warmly).

Second, participants completed eight items that assessed perceived intragroup similarity. Four items assessed the perceived intragroup similarity of Blacks $(\alpha=.86)$ and four assessed the perceived intragroup similarity of Whites ( $\alpha=.84)$. These items included, 'Overall, how similar or dissimilar are Blacks [Whites] to each other?' 'How similar or dissimilar are Whites [Blacks] to each other in terms of their life goals?' 'How similar or dissimilar to each other are Whites [Blacks] in terms of their behaviors?' and 'How similar or dissimilar are Whites [Blacks] to each other in terms of their beliefs about race relations?' Participants answered each question using a scale from 1 (very dissimilar) to 7 (very similar).

Third, participants completed a measure that we developed following Wolsko et al. (2000). Participants were asked to indicate the extent to which they believed that each of eight strategies would or would not improve relations between groups in the US. Four items were intended to assess multiculturalism and four were intended to assess a colorblind ideology (see Table 1). Participants rated each statement on a scale from 1 (not likely to improve relations between groups) to 7 (likely to improve relations between groups). Psychometric information about this scale is provided in the Results section.

Finally, participants completed measures of intergroup familiarity and ethnic identity. Participants indicated the ethnicity of their close friends, the people who lived in their neighborhoods, and the people with whom they visited on a 5 -point scale $(1=$ all ethnic minorities, $3=$ about half and half, $5=$ all Whites; $\alpha=.69$ ). They also indicated the extent to which they agreed with two items from Phinney's (1992) Multigroup Ethnic Identity Measure (i.e. 'I have a clear sense of my ethnic background and what it means for me' and 'I have a strong sense of belonging to my own ethnic group'; $\alpha=.72$ ), using 7 -point scales ( $1=$ strongly disagree and 7 = strongly agree $)$.

Table 1. Multicultural and colorblind ideology rotated factor loadings in Study 1

\begin{tabular}{|c|c|c|}
\hline Ideology item & $\begin{array}{l}\text { Multicultural } \\
\text { (Factor } 1)\end{array}$ & $\begin{array}{l}\text { Colorblind } \\
\text { (Factor 2) }\end{array}$ \\
\hline Adopting a multicultural perspective. & .83 & .03 \\
\hline Recognizing that there are differences between ethnic groups. & .82 & .07 \\
\hline $\begin{array}{l}\text { Emphasizing the importance of appreciating group differences between } \\
\text { ethnic groups. }\end{array}$ & .78 & -.04 \\
\hline Accepting each ethnic group's positive and negative qualities. & .63 & .45 \\
\hline Judging one another as individuals rather than members of an ethnic group & -.05 & .80 \\
\hline Recognizing that all people are basically the same regardless of their ethnicity. & -.16 & .78 \\
\hline Recognizing that all people are created equally regardless of their ethnicity. & .33 & .64 \\
\hline $\begin{array}{l}\text { Adopting a colorblind perspective in which one's ethnic group membership } \\
\text { is considered unimportant. }\end{array}$ & .41 & .59 \\
\hline
\end{tabular}

Notes: $\mathrm{N}=87$. Boldface indicates item loading on that factor. 


\section{Results}

Familiarity and identity Tests of ethnic group differences in intergroup familiarity indicated that, as expected, Black participants were nearly equally familiar with ethnic minorities and Whites $(M=2.72, S D=0.71)$, whereas White participants were more familiar with Whites than with ethnic minorities $(M=3.83, S D=0.48)$ $\left(F(1,83)=62.46, p<.0001, \eta^{2}=.42\right)$. Also, consistent with previous research (Phinney, 1992), Blacks reported greater identification with their ethnic group than did Whites $(M s=5.80$ and 4.39, respectively; $S D \mathrm{~s}=1.45$ and 1.41 ) $\left(F(1,85)=15.30, p<.001, \eta^{2}=.14\right)$. These results suggest that despite their participation in the diversity program, participants exhibited the significant ethnic group differences in outgroup familiarity and ethnic identity that would be expected based on previous research (e.g. Judd et al., 1995; Phinney, 1992).

Multicultural versus colorblind ideology We conducted a principal components analysis of the eight ideology items to determine their empirical structure. The analysis revealed only two eigenvalues that were greater than 1 . These two components were rotated using a varimax criterion. The first factor accounted for $39 \%$ of the variance (eigenvalue $=3.12$ ) and consisted of the four items that were intended to assess endorsement of a multicultural ideology (see Table 1). The second factor accounted for $22 \%$ of the variance (eigenvalue $=1.78$ ) and consisted of the four items that were intended to assess endorsement of a colorblind ideology. The results of this analysis were thus consistent with our a priori conceptual distinction between multicultural and colorblind ideologies. We therefore averaged across each set of items to form indices of the extent to which participants endorsed multicultural $(\mathrm{a}=.78)$ and colorblind $(\mathrm{a}=.69)$ ideologies.

The two measures were moderately correlated for Blacks $(r(18)=.51, p=.02)$, and Whites $(r(65)=.21, p=.09)$, which is not surprising for both methodological and conceptual reasons. Methodologically, the two sets of items were somewhat positively valenced to minimize social desirability issues; we were concerned that participants not perceive one strategy to be more (politically) correct than another. Conceptually, we see no reason that the two ideologies be considered as mutually exclusive or contradictory; positive and negative consequences seem likely to ensue from both ideologies, depending on specific circumstances. We consider this issue more fully in the General Discussion.

Ideology ratings were analyzed as a function of ideology (multicultural, colorblind) and participant Group (Black, White), an analysis of variance (ANOVA) with repeated measures on the first factor. The analysis revealed a main effect of Participant Group $(F(1,85)=8.41$, $\left.p<.01, \eta^{2}=.08\right)$, a main effect of Ideology $\left(F(1,85)=10.74, p<.01, \eta^{2}=.10\right)$, as well as the predicted participant group $\times$ ideology interaction $\left(F(1,85)=7.38, p<.01, \eta^{2}=.07\right)$. As the means in Table 2 indicate, White participants' ratings were generally higher than were Black participants' ratings. Participants also more strongly endorsed a multicultural than a colorblind ideology, which is consistent with their choice to participate in a diversity program. The interaction indicated that endorsement of multiculturalism relative to colorblindness was greater for Blacks than for Whites. Simple effects tests further indicated that the multiculturalcolorblind difference was significant for Blacks $\left(F(1,20)=13.46, p<.01, \eta^{2}=.34\right)$, but not for Whites $(p=.57)$. In addition, Whites endorsed a colorblind ideology more strongly than did Blacks $\left(F(1,85)=15.99, p<.001, \eta^{2}=.15\right)$. The simple effect test for multiculturalism was not significant $(p=.48){ }^{1}$

Perceived intragroup similarity We analyzed judgments of perceived intragroup similarity as a function of target group (Black, White) and participant group (Black, White), an ANOVA with repeated measures on the first factor. The analysis revealed a main effect of Participant Group $\left(F(1,85)=4.13, p<.05, \eta^{2}=.04\right)$, and a target group $\times$ participant group interaction $\left(F(1,85)=8.54, p<.01, \eta^{2}=.08\right)$. As the means in Table 2 indicate, Black participants perceived greater similarity within both ethnic groups than did White participants. Thus, as expected, Black participants exhibited stronger stereotypes overall than did White participants. In addition, 
Table 2. Mean ideology, perceived group similarity, and ethnocentrism judgments in Study 1

\begin{tabular}{lcc}
\hline & \multicolumn{2}{c}{ Participant group } \\
\cline { 2 - 3 } & Blacks & Whites \\
\hline Ideology & & \\
Multicultural & 5.35 & 5.57 \\
& $(1.33)$ & $(1.20)$ \\
Colorblind & 4.25 & 5.47 \\
& $(1.39)$ & $(1.14)$ \\
Perceived group similarity & & \\
Black target group & 3.60 & 3.34 \\
& $(1.44)$ & $(1.38)$ \\
White target group & 4.01 & 2.98 \\
& $(1.32)$ & $(1.30)$ \\
Thermometer ratings & & \\
Black target group & 84.74 & 74.78 \\
White target group & $(17.20)$ & $(18.57)$ \\
& 61.32 & 80.85 \\
& $(15.80)$ & $(17.63)$ \\
\hline
\end{tabular}

Note: Numbers in parentheses are standard deviations.

both Black and White participants perceived greater similarity among out-group members than among in-group members, which is the classic out-group homogeneity effect (Park \& Rothbart, 1982) that Judd et al. (1995) found among Black participants, but not among Whites. Simple effects tests indicated that the in-group-out-group difference was significant for both Black $(F(1,19)=3.76, p=.07$, $\left.\eta^{2}=.12\right)$, and White participants $(F(1,66)=7.67$, $\left.p<.01, \eta^{2}=.09\right)$.

Finally, we examined the relationship between endorsement of a multicultural relative to a colorblind ideology and perceived group similarity for Black versus White participants. We conducted the same mixed model analysis as above, this time including the multicultural colorblind ideology difference (a centered continuous predictor) and the interaction between participant group (contrast-coded) and multicultural versus colorblind ideology. ${ }^{2}$ The interaction was significant $(F(1,83)=5.21, p=.03$, $\left.\eta^{2}=.05\right)$. As Figure 1 indicates, stronger endorsement of a multicultural relative to a colorblind ideology was associated with stronger stereotypes (i.e. greater perceived group similarity) among
Black participants and weaker stereotypes among White participants. The direction of the relationship for Black participants was thus consistent with the experimental findings of Wolsko et al. (2000). But the relationship for White participants indicated that stronger endorsement of colorblindness relative to multiculturalism predicted stronger stereotypes. ${ }^{3}$

Ethnocentrism Judgments on the feeling thermometer task were analyzed as a function of target group (Black, White) and participant group (Black, White) with repeated measures on the first factor. The analysis revealed a main effect of target group $(F(1,84)=13.97, p<.001$, $\left.\eta^{2}=.13\right)$, and a target group $\times$ participant group interaction $(F(1,84)=40.38, p<.001$, $\left.\eta^{2}=.32\right)$. Overall, Blacks were judged more positively than were Whites (see Table 2 ). However, this effect was qualified by an interaction indicating ethnocentrism. Both participant groups judged their in-groups more positively than their out-groups. Simple effects tests indicated that the in-group-out-group difference was significant for both Blacks $(F(1,18)=26.41$, $\left.p<.001, \eta^{2}=.57\right)$ and Whites $(F(1,66)=8.29$, $\left.p<.01, \eta^{2}=.10\right)$.

An additional analysis indicated that multicultural versus colorblind ideology predicted more positive judgments of the Black versus White target group $(r(82)=.27, p=.01)$. However, the relationship was not significant when participant ethnicity was controlled $(p=.14)$. The relationship between ideology and thermometer judgments did not depend on participant ethnicity $(p>.20)$.

\section{Discussion}

Overall, participants more strongly endorsed a multicultural than a colorblind ideology, which seems consistent with their participation in a diversity program. As expected, however, this difference depended on participant ethnicitythe tendency to endorse multiculturalism more than colorblindness was greater among Black than White participants. Simple effects tests further indicated that White participants more strongly endorsed a colorblind ideology than did Blacks and Black participants more strongly 


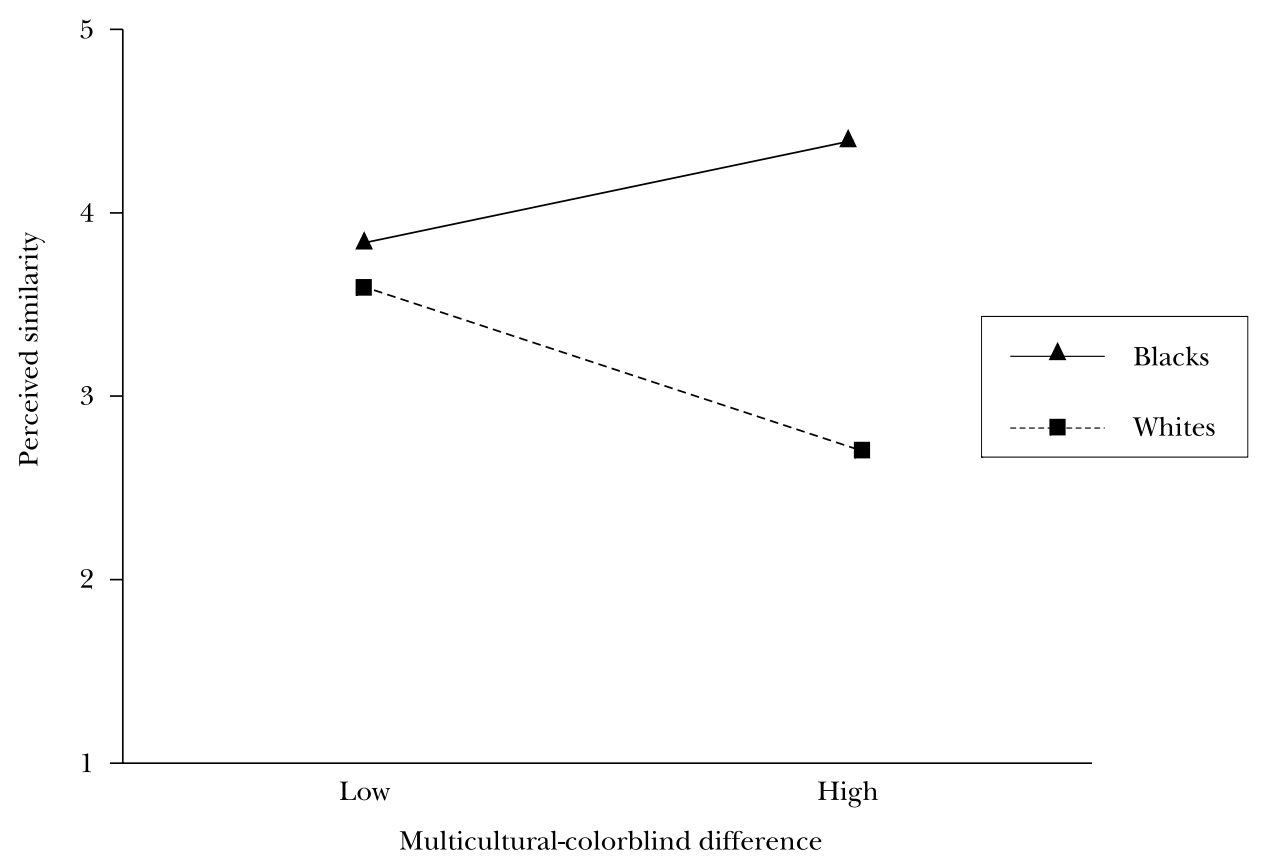

Figure 1. Relationship between ideology and perceived group similarity for Black and White participants.

endorsed a multicultural than a colorblind ideology.

To our knowledge, this study is the first to demonstrate out-group homogeneity among Blacks and Whites. Both Black and White participants perceived greater similarity among the members of the out-group than among the members of the in-group. In addition, both Black and White participants felt more warmly toward the in-group than the out-group, that is, ethnocentrism. The demonstration of outgroup homogeneity and ethnocentrism seems particularly remarkable given that the data were gathered from participants in a diversity program who completed explicit measures of stereotypes and prejudice. The data also revealed that Black participants judged Whites and Blacks to be less variable (i.e. lower intragroup similarity) than did White participants. Participants also felt more warmly toward the Black target group than the White target group. The latter two findings are consistent with those of Judd et al. (1995).

Finally, Black participants who more strongly endorsed a multicultural relative to a colorblind ideology perceived greater intragroup similarity, whereas the reverse was true among White participants. Thus, White participants who more strongly endorsed a colorblind relative to a multicultural ideology exhibited stronger stereotypes, which is consistent with the notion that a colorblind ideology allows people to ignore, rather than address, stereotypic beliefs (Flagg, 1993; Gotanda, 1995). To examine this idea further, we examined the correlations between internal motivation to control prejudice (Plant \& Devine, 1998), which had also been assessed, and group perceptions for White participants. Internal motivation to control prejudice was associated with less perceived out-group homogeneity $(r(65)=-.44, p<.01)$, and less ethnocentrism $(r(65)=-.28, p<.02)$. It was also associated with stronger endorsement of a multicultural relative to colorblind ideology $(r(65)=.28, p=.02)$, which is consistent with the view that multiculturalism represents a more proactive approach to improving intergroup relations, whereas colorblindness-at least among many Whites at this point in history—may 
represent a justification for ignoring ethnic group differences.

We consider the findings from the present study to be quite remarkable, particularly given the relatively small number of Black participants $(n=20)$, the use of explicit measures, and the fact that participants were people who voluntarily attended a diversity program. Nevertheless, the present study was limited. Perceived group variability was assessed, using only four global similarity items that did not refer to specific stereotype-relevant attributes; the scales for ethnocentrism and ethnic identity contained only two items. Given the lack of data on differences between Black and White participants in interethnic ideology, the unique sample, and our use of new and abbreviated measures, it seemed important to determine whether our findings would replicate in a different sample. We also wished to measure ethnic identity and intergroup experiences more fully in order to examine ethnic group differences in ideology and intergroup perceptions (and the relations between the two) independently of ethnic group differences in identity and intergroup experiences. We therefore conducted a second study of Black and White college students.

\section{Study 2}

Black and White college students completed a questionnaire that included measures of stereotypes and ethnocentrism, current and past experiences with Blacks and Whites, and ethnic identity, as well as our measure of multiculturalism and colorblindness. Stereotypes and ethnocentrism were assessed using the range and percentage estimation tasks. The range task yields a measure of perceived group variability; the percentage estimation task yields measures of perceived group stereotypicality and perceived group positivity (Judd et al., 1995; Park, Judd, \& Ryan, 1991; Ryan, 1996, 2002). Intergroup experiences and ethnic identity were assessed using an adapted version of the Multicultural/Multiracial Experience Inventory (MEI; Ramirez, 1998) and Phinney's (1992) measure of ethnic identity.

\section{Method}

Participants Seventy-three Black (26 male, 47 female) and 88 White (27 male, 61 female) undergraduates at the University of Nebraska at Omaha participated in the study. All of the White students and 29 Black students participated in exchange for extra credit in their psychology classes. Forty-four Black students were recruited via class announcements and fliers posted across campus; they participated in exchange for US $\$ 10$ each.

Procedure Participants completed a questionnaire individually or in small groups. The questionnaire included two tasks that assessed perceived group dispersion, stereotypicality, and positivity. Participants first indicated the percentage of group members (from $0 \%$ to $100 \%$ ) who possessed each of eight stereotyperelevant attributes. They then completed the range estimation task in which they indicated where they believed the highest and lowest group members would fall on each of the same eight attribute dimensions. Participants provided responses on 20-point scales (1 to 20) labeled only at the endpoints (e.g. Not athletic and Athletic).

The eight attributes used in these tasks varied with respect to stereotypicality and valence. Four attributes were stereotypic of Blacks and counterstereotypic of Whites. Half were positive (i.e. athletic, streetwise) and half were negative (i.e. poor, hostile). The remaining four attributes were stereotypic of Whites and counterstereotypic of Blacks. Again, half were positive (i.e. intelligent, ambitious) and half were negative (i.e. uptight, spoiled). Note that participants judged both target groups on the same set of attribute dimensions; group differences are thus unconfounded with attribute differences. Target group order was counterbalanced across participants.

Next, participants completed the same measure of beliefs about the likelihood that multicultural and colorblind ideologies would improve intergroup relations as was used in Study 1 (see Table 1), Phinney's (1992) 21-item measure of ethnic identity and, finally, an 
adapted version of the MEI (Ramirez, 1998). In addition to overall ethnic identity $(\alpha=.88)$, Phinney's scale yields measures of affirmation and belonging, that is, feelings of pride and attachment to one's ethnic group $(\alpha=.83)$; ethnic identity achievement, that is, exploration of one's ethnic background ( $\alpha=.82)$; and ethnic behaviors and practices, that is, involvement in social activities with the members of one's group and participation in cultural traditions $(\alpha=.35)$.

The MEI (Ramirez, 1998) was adapted to assess participants' experiences with Blacks and Whites. Seventeen items assessed experience with Whites versus Blacks (see Table 3), using a scale from 1 (almost entirely African Americans) to 5 (almost entirely Whites) $(\alpha=.91)$. Contact with Blacks and with Whites was assessed using 3 items each (items 18 through 20 in Table 3). Participants rated each of these items on a 7 -point scale $(1=$ never, $7=$ extensively $)(\alpha \mathrm{s}=.88$ for Blacks and .89 for Whites).

\section{Results}

As expected, Blacks scored significantly higher than Whites on Phinney's (1992) measures of ethnic identity, affirmation and belonging, ethnic identity achievement, and ethnic behaviors and practices (see Table 4). In addition, White participants had more experience with Whites, whereas Black participants had more experiences with Blacks. Both Blacks and Whites also had significantly more current contact with their in-group than with their out-group.

We computed a single measure of intergroup experiences by computing the out-group-ingroup difference in the two contact measures and an out-group-in-group measure of experiences (i.e. reverse scoring items so that higher values would reflect greater experience with the outgroup relative to the in-group). We then standardized and averaged across these two scores $(\alpha=.81)$. Phinney's (1992) single measure of ethnic identity and the intergroup experiences measure were treated as continuous (centered)

Table 3. Items assessing intergroup experiences in Study 2

1. The ethnic composition of the neighborhood in which I lived...

...before I started attending school was...

... while I attended elementary school was...

...while I attended middle school was...

...while I attended high school was...

2. My childhood friends who visited my home and related well to my parents were...

3. The teachers and counselors with whom I have had the closest relationships have been...

4. The people who have most influenced me in my education have been...

5. In high school, my close friends were...

6. The ethnic backgrounds of the people I have dated have been...

7. In the job(s) I have had, my close friends have been...

8. The people with whom I have established close meaningful relationships have been...

9. At present, my close friends are...

10. My close friends at work are (were)...

11. I enjoy going to gatherings at which the people are...

12. When I study or work on a project with others, I am usually with persons who are...

13. When I am involved in group discussions where I am expected to participate, I prefer a group of people who are...

14. I am active in organizations or social groups in which the majority of the members are...

15. When I am with my friends, I usually attend functions where the people are...

16. When I discuss personal problems or issues, I discuss them with people who are...

17. I most often spend time with people who are...

18. I attend functions that are predominantly Black [White] in nature.

19. I visit the homes of Black [White] persons.

20. I invite Black [White] persons to my home.

Note: Adapted from Ramirez (1998). 
Table 4. Mean judgments of ethnic identity and intergroup experiences in Study 2

\begin{tabular}{|c|c|c|c|}
\hline & \multicolumn{3}{|c|}{ Participant group } \\
\hline & Blacks & Whites & $F$ \\
\hline \multicolumn{4}{|l|}{ Ethnic identification } \\
\hline Identity & $\begin{array}{c}3.42 \\
(0.39)\end{array}$ & $\begin{array}{c}2.78 \\
(0.48)\end{array}$ & $84.91 * * *$ \\
\hline Affirmation and belonging & $\begin{array}{c}3.73 \\
(0.33)\end{array}$ & $\begin{array}{c}3.09 \\
(0.56)\end{array}$ & $75.26 * * *$ \\
\hline Ethnic identity achievement & $\begin{array}{c}3.27 \\
(0.46)\end{array}$ & $\begin{array}{c}2.55 \\
(0.55)\end{array}$ & $80.40 * * *$ \\
\hline Behaviors and practices & $\begin{array}{c}3.14 \\
(0.78)\end{array}$ & $\begin{array}{c}2.82 \\
(0.67)\end{array}$ & $8.17 *$ \\
\hline \multicolumn{4}{|l|}{ Intergroup experiences } \\
\hline Experiences with Whites vs. Blacks & $\begin{array}{c}2.40 \\
(0.66)\end{array}$ & $\begin{array}{c}4.20 \\
(0.51)\end{array}$ & $385.31 * * *$ \\
\hline $\begin{array}{l}\text { Current contact } \\
\text { with Blacks }\end{array}$ & $\begin{array}{c}5.84 \\
(1.02)\end{array}$ & $\begin{array}{c}3.12 \\
(1.26)\end{array}$ & $219.80 * * *$ \\
\hline with Whites & $\begin{array}{c}3.72 \\
(1.50)\end{array}$ & $\begin{array}{c}6.09 \\
(0.94)\end{array}$ & $149.87 * * *$ \\
\hline
\end{tabular}

Note: Numbers in parentheses are standard deviations. $* p<.01 ; * * p<.001 ; * * * p<.000$.

predictors in subsequent analyses to determine whether ethnic group differences in contact or ethnic identity might at least partially account for ethnic group differences in ideologies (cf. Verkuyten, 2006) and intergroup perceptions.

Multicultural versus colorblind ideology We conducted two confirmatory factor analyses (CFAs) to verify that our multicultural and colorblind ideology items represented two distinct constructs. The 2 Factor Model tested the expected model in which multicultural and colorblind ideologies were separate but correlated constructs. A 1 Factor Model in which all items loaded on a single intergroup ideology factor was run as a comparison model. In both models, we allowed two closely related items (i.e. 'Recognizing that all people are created equally regardless of their ethnicity', 'Recognizing that all people are basically the same regardless of their ethnicity') to covary. Both CFAs were conducted with MPlus software using the rescaled maximum likelihood procedure to correct for non-normality (Satorra \& Bentler, 1994). The fit of each model was assessed using the comparative fit index (CFI), the standardized root mean square residual (SRMR), and the chi-square test of model fit. CFI and SRMR are better fit indices than chi-square because they are less influenced by sample size. According to $\mathrm{Hu}$ and Bentler (1999), good model fit would be indicated by a CFI $\geq .95$ and an SRMR $<.06$.

Results indicated that the 2 Factor Model fit well with the data, with a CFI of .95 and a SRMR of .05 and all indicators loading highly on the two latent variables (see Figure 2). In contrast, the 1 Factor Model fit less well, with a CFI of .92 and an SRMR of .06. We compared the two models using the Satorra-Bentler scaling-corrected test statistic (Satorra \& Bentler, 2001). As predicted, the 2 Factor Model fit the data significantly better than did the 1 Factor Model $\left(\chi^{2} \Delta(1)=8.06\right.$, $p<.005)$, signifying that multicultural and colorblind ideologies were distinct constructs measured by our scale. As in Study 1, the two measures were correlated for both Blacks $(r(71)=.57$, $p<.001)$ and Whites $(r(86)=.50, p<.001){ }^{4}$

Ideology ratings were analyzed as a function of ideology (multicultural, colorblind) and participant group (Black, White), an ANOVA with 


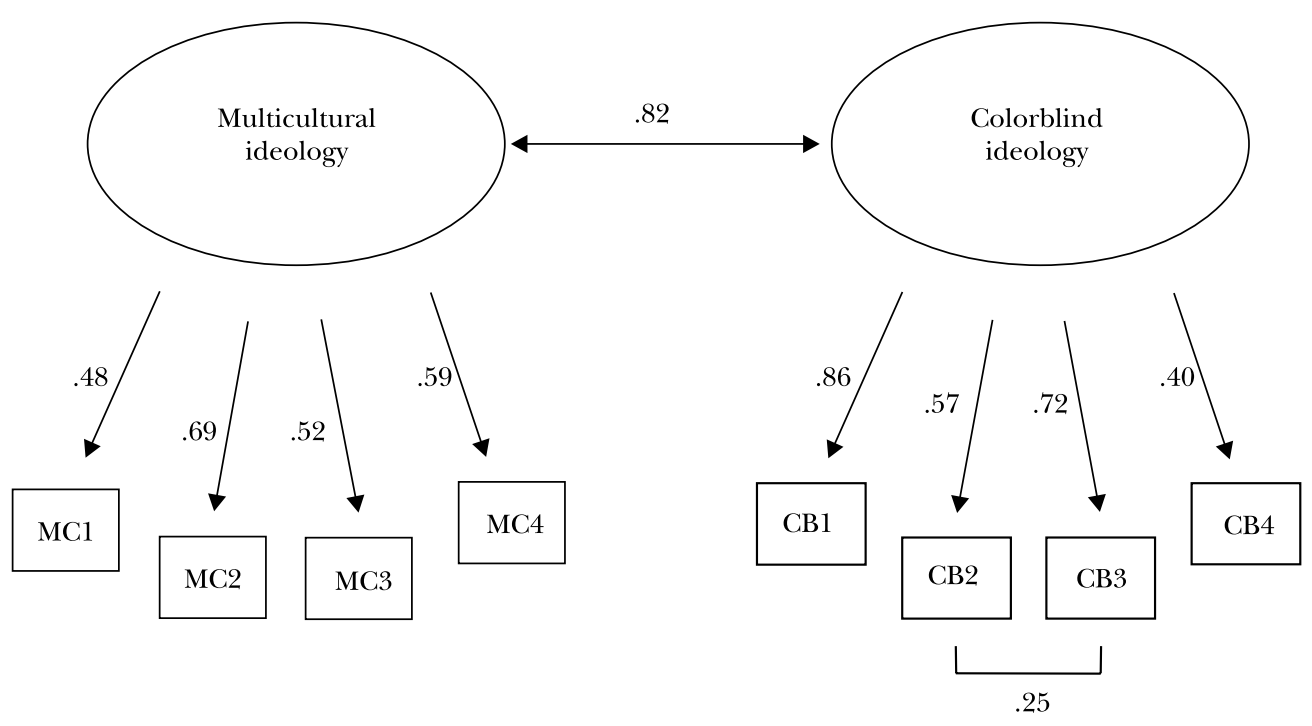

Figure 2. Confirmity factor analysis of ideology items.

repeated measures on the first factor. The only significant effect was the Ideology $\times$ Participant Group interaction $(F(1,159)=7.54, p<.01$, $\left.\eta^{2}=.04\right)$. As predicted, White participants endorsed colorblindness $(M=5.74)$ more strongly than did Black participants $(M=5.36)$, whereas Black participants endorsed multiculturalism $(M=5.48)$ more strongly than did White participants $(M=5.36)$. Simple effects tests indicated that Whites endorsed a colorblind ideology more strongly than did Black participants $\left.F(1,159)=3.51, p=.06, \eta^{2}=.02\right)$, and more strongly than a multicultural ideology $\left(F(1,87)=3.92, p=.05, \eta^{2}=.03\right)$. The simple multicultural-colorblind difference for Black participants was significant $(F(1,72)=3.57$, $\left.p=.06, \eta^{2}=.03\right)$, but the simple Black-White ethnic group difference in multiculturalism was not $(p=.46)$. A mixed model analysis of covariance (ANCOVA) in which ethnic identity and intergroup experiences were controlled yielded the same significant interaction $(F(1$, $\left.157)=9.14, p<.01, \eta^{2}=.05\right)$, and no effects of ethnic identity $(p>.50)$. Interestingly, however, more intergroup experience predicted weaker endorsement of a multicultural relative to a colorblind ideology $(F(1,157)=4.61, p=.03$, $\left.\eta^{2}=.02\right)$; this effect did not depend on ethnicity or ethnic identity (both $p s>.49$ ).

Perceived dispersion A measure of dispersion was computed from the range task by subtracting judgments of the lowest group member from those of the highest group member on each attribute dimension and then averaging across dimensions within each of the four attribute types (stereotypic vs. counterstereotypic $\times$ positive vs. negative). Higher values indicate greater perceived variability. Dispersion judgments were analyzed as a function of target group (Black, White), attribute stereotypicality (stereotypic, counterstereotypic), attribute valence (positive, negative), and participant group (Black, White), an ANOVA with repeated measures on the first three factors.

The two primary effects of interest were significant: the main effect of participant group $\left(F(1,159)=40.24, p<.001, \eta^{2}=.20\right)$, and the target group $\times$ participant group interaction $\left(F(1,159)=16.71, p<.001, \eta^{2}=.09\right)$. No other effects were significant (all $p s>.19$ ). The means, collapsing across attribute type, are presented in Table 5. Consistent with previous research (Judd et al., 1995) and Study 1, Black participants 
Table 5. Mean judgments of perceived group dispersion, stereotypicality, and positivity in study 2

\begin{tabular}{ccccc}
\hline & \multicolumn{2}{c}{ Participant group } \\
\cline { 2 - 5 } & \multicolumn{2}{c}{ Blacks } & \multicolumn{2}{c}{ Whites } \\
\cline { 2 - 5 } Stereotype measure & \multicolumn{2}{c}{ Target group } & \multicolumn{2}{c}{ Target group } \\
\cline { 2 - 5 } Dispersion & Black & White & Black & White \\
& 13.34 & 12.71 & 16.13 & 16.72 \\
Stereotypicality & $(3.66)$ & $(4.18)$ & $(3.43)$ & $(2.77)$ \\
& 12.46 & 30.61 & 6.81 & 20.38 \\
Positive attributes & $(16.58)$ & $(18.09)$ & $(13.81)$ & $(12.73)$ \\
& 5.02 & 30.83 & 5.93 & 21.57 \\
Negative attributes & $(20.95)$ & $(22.24)$ & $(19.17)$ & $(16.13)$ \\
Positivity & 19.90 & 30.40 & 7.70 & 19.19 \\
Stereotypic attributes & $(19.70)$ & $(20.64)$ & $(16.91)$ & $(16.70)$ \\
Counterstereotypic attributes & 30.89 & 1.19 & 21.38 & 11.29 \\
& $(14.10)$ & $(12.71)$ & $(17.01)$ & $(13.86)$ \\
& 23.45 & 1.40 & 20.49 & 12.48 \\
& $(17.19)$ & $(17.47)$ & $(18.59)$ & $(18.65)$ \\
& 38.33 & 0.97 & 22.27 & 10.10 \\
& $(19.48)$ & $(16.85)$ & $(22.48)$ & $(15.85)$ \\
\hline
\end{tabular}

Note: Numbers in parentheses are standard deviations.

generally perceived less dispersion in both groups than did White participants. In other words, Blacks exhibited stronger stereotypes than did Whites. The interaction reflected the classic out-group homogeneity effect; participants perceived their in-groups to be more variable than their out-groups. Simple effects tests indicated that the in-group-out-group difference was significant for both Black $\left(F(1,72)=6.14, p=.02, \eta^{2}=.07\right)$ and White participants $\left(F(1,87)=11.81, p<.001, \eta^{2}=.11\right)$. These effects remained when intergroup experiences and ethnic identity were controlled (both $p \mathrm{~s}<.001)$. All other effects, including interactions among participant group, ethnic identity, and intergroup experiences, were nonsignificant $(p s>.12)$.

Recall that we expected that endorsement of a multicultural relative to a colorblind ideology would predict stronger stereotypes (i.e. less perceived dispersion) among Black participants, but not among White participants. This hypothesis was tested by adding the multiculturalcolorblind difference score (a continuous centered predictor) and its interaction with participant group (contrast-coded) to the mixed model analysis of variance described above. This analysis, which was equivalent to a mixed model ANCOVA, yielded the expected interaction $\left(F(1,157)=7.73, p<.01, \eta^{2}=.04\right)$. Simple effects tests indicated that, as expected, Blacks who more strongly endorsed a multicultural versus colorblind ideology perceived less dispersion $\left(F(1,73)=4.62, p=.03, \eta^{2}=.05\right)$. The relationship for Whites was marginally significant in the opposite direction $(F(1,86)=3.03, p=.08$, $\left.\eta^{2}=.02\right)$. As in Study 1, then, Black participants who more strongly endorsed multiculturalism relative to colorblindness exhibited stronger stereotypes, whereas among White participants stronger endorsement of colorblindness predicted stronger stereotypes.

Perceived stereotypicality Percentage estimates were analyzed as a function of attribute stereotypicality (stereotypic, counterstereotypic), attribute valence (positive, negative), target group (Black, White), and participant group (Black, White), an ANOVA with repeated measures on the first three factors. For clarity of presentation, we focus in this section on effects involving attribute stereotypicality and report 
effects involving attribute valence, which assess ethnocentrism, in the section that follows. However, in each section we note any effects that were qualified by the other factor.

The mean stereotypicality judgments (i.e. mean stereotypic - counterstereotypic differences) as a function of target group, participant group, and attribute valence are reported in Table 5. Participants judged stereotypic attributes to be more prevalent than counterstereotypic attributes $(F(1,159)=365.42, p<.001$, $\left.\eta^{2}=.69\right)$, confirming our choice of stereotypic and counterstereotypic attributes. More importantly, the analysis indicated that Black participants perceived greater stereotypicality than did White participants $(F(1,159)=18.66, p<.001$, $\left.\eta^{2}=.10\right)$, again suggesting that Blacks had stronger stereotypes than did Whites. Black participants also judged the out-group to be more stereotypic than the in-group, whereas White participants judged the out-group to be less stereotypic than the in-group $(F(1,159)=$ $\left.102.38, p<.0001, \eta^{2}=.60\right)$. This effect can also be interpreted as indicating that, consistent with Judd et al. (1995), participants judged the White target group to be more stereotypic than the Black target group. This tendency was greater for positive than negative attributes $\left(F(1,159)=13.20, p<.001, \eta^{2}=.07\right)$. These effects persisted when intergroup experiences and ethnic identity were controlled (all $p$ s $<.001$ ). The latter analysis also indicated that participants who had more intergroup experiences perceived the groups to be less stereotypic $\left(F(1,157)=4.58, p<.04, \eta^{2}=.02\right)$. All other effects, including interactions among predictors (which were tested in a separate analysis), were nonsignificant $(p \mathrm{~s}>.10)$.

Next, we examined the relationship of multicultural versus colorblind ideology with stereotype strength by adding the multiculturalcolorblind difference score and its interaction with ethnicity (contrast-coded) to the mixed model ANOVA described above. This ANCOVA yielded an effect of ideology $(F(1,157)=4.00$, $\left.p<.05, \eta^{2}=.02\right)$, as well as the expected attribute stereotypicality $\times$ participant group $\times$ ideology interaction $\left(F(1,157)=6.45, p<.02, \eta^{2}=.03\right)$. Thus, overall, participants who endorsed multi- culturalism more than colorblindness generally perceived the groups more stereotypically. However, this relationship depended on ethnicity such that Black participants who more strongly endorsed a multicultural relative to colorblind ideology perceived the groups to be more stereotypic, whereas there was a slight tendency in the opposite direction for Whites. Simple effects tests indicated that the relationship was significant for Blacks $(F(1,71)=8.12, p<.01$, $\left.\eta^{2}=.09\right)$, but not for Whites $(F<1)$. Again, then, Black participants exhibited the expected positive relationship between endorsement of a multicultural versus colorblind ideology and stronger stereotypes and this relationship was significantly different from the relationship for Whites. However, the simple relationship for Whites was not significant. Additional analyses in which intergroup experiences and ethnic identity were included yielded the same effects. And, once again, participants who reported more intergroup experiences tended to perceive the groups less stereotypically, overall $(p=.09)$; all other effects, including interactions among predictors, were nonsignificant $(p s>.33)$.

Ethnocentrism The mean positivity judgments (i.e. mean positive-negative differences) are reported in Table 5. The ANOVA indicated that participants judged positive attributes to be more prevalent, overall, than negative attributes $\left(F(1,159)=363.87, p<.001, \eta^{2}=.69\right)$. In addition, Blacks were judged more positively than were Whites $\left(F(1,159)=160.76, p<.001, \eta^{2}=.50\right)$, especially on counterstereotypic attributes $\left(F(1,159)=13.20, p<.001, \eta^{2}=.07\right)$. The attribute valence $\times$ target group interaction was qualified by participant group $(F(1,159)=39.06$, $\left.p<.001, \eta^{2}=.19\right)$. This triple interaction indicated that the Black target group was judged more positively by Blacks, whereas the White target group was judged more positively by Whites, which is consistent with ethnocentrism. However, it can also be interpreted as indicating that Black participants judged the out-group less positively than the in-group, whereas Whites judged the out-group more positively than the in-group. Although the latter interpretation may seem surprising, it is consistent with other 
research using the percentage estimation task (Judd et al., 1995; Wolsko et al., 2000). Once again, these effects remained when intergroup experiences and ethnic identity were controlled $(p s<.001)$. In addition, participants who reported more intergroup experiences exhibited less ethnocentrism $(F(1,157)=11.63, p<.001$, $\left.\eta^{2}=.06\right)$. All other effects, including interactions among predictors, were nonsignificant $(p \mathrm{~s}>.10)$.

Finally, we examined the relationship between ideology and ethnocentrism. We computed the in-group-out-group difference in perceived group positivity (i.e. ethnocentrism) and regressed it on ethnicity (contrast-coded), the ideology difference score (a centered continuous predictor), and the interaction between them, controlling for intergroup experiences and identity, which were treated as centered continuous predictors. ${ }^{5}$ The analysis revealed the predicted effect in which participants who more strongly endorsed a multicultural relative to a colorblind ideology exhibited less ethnocentrism $\left(F(1,155)=4.58, p=.03, \eta^{2}=.02\right)$. This relationship did not depend on participant group $(p>.27)$. A significant effect of intergroup experiences $(F(1,155)=13.18, p<.001$, $\left.\eta^{2}=.07\right)$ further indicated that participants who reported more intergroup experiences exhibited less ethnocentrism.

\section{Discussion}

Once again, the tendency to believe that multiculturalism would improve intergroup relations more than would colorblindness was greater among Black than White participants. The pattern of means was remarkably similar to that of Study 1. Blacks believed that multiculturalism was more likely than colorblindness to improve intergroup relations and Whites believed more strongly than did Blacks that colorblindness would improve intergroup relations. Interestingly, participants did not endorse a multicultural ideology more strongly than a colorblind ideology. Thus, only participants who had chosen to attend a diversity program (i.e. Study 1 participants) expressed stronger support of a multicultural than a colorblind ideology.
Black participants also again exhibited stronger stereotypes (i.e. less dispersion and greater stereotypicality) than did White participants and both Black and White participants exhibited outgroup homogeneity, perceiving less dispersion in the out-group than in the in-group. Black participants also perceived the out-group to be more stereotypic and less positive than their in-group, whereas White participants perceived the Black target group to be less stereotypic and more positive (Judd et al., 1995). In other words, everyone judged the Black target group to be less stereotypic and more positive than the White target group. The in-group-out-group difference in perceived group positivity was also significant. Although everyone judged Blacks more positively than Whites, this was significantly less true of White participants.

The relationships of ideology to stereotype strength and ethnocentrism were also largely as expected. Among Black participants, stronger endorsement of a multicultural relative to a colorblind ideology was associated with lower perceived group dispersion and greater perceived group stereotypicality, whereas stronger endorsement of a colorblind than a multicultural ideology was associated with lower perceived dispersion among White participants. In addition, participants who more strongly endorsed a multicultural relative to colorblind ideology exhibited less ethnocentrism.

Finally, the effects of intergroup experiences seem worth noting. As expected, Blacks reported greater intergroup experiences than did Whites. When this difference was controlled, intergroup experiences were associated with weaker endorsement of multiculturalism relative to colorblindness, lower perceived group stereotypicality, and less ethnocentrism; these relationships did not depend on ethnicity.

\section{General discussion}

The purpose of this research was to examine multicultural and colorblind ideologies, stereotypes, and ethnocentrism among both Black and White Americans. We expected that Blacks were more likely to believe that multiculturalism 
would improve intergroup relations, whereas Whites were more likely to believe in the benefits of a colorblind ideology for intergroup relations inasmuch as Blacks and Whites have been shown to differ with respect to the meaning and importance of ethnicity. Whites tend to be socialized to ignore group membership (Judd et al., 1995) and are generally less aware of the effects of race on their daily lives (Swim \& Miller, 1999). In contrast, ethnicity identity is stronger among Black individuals, and messages emphasizing cultural pride and awareness are routinely incorporated into the parenting practices of Black Americans (Caughy et al., 2002; Thornton, 1997).

The results were largely consistent with predictions and the pattern of means was remarkably similar across the two studies. Significant interactions indicated that the tendency to believe that multiculturalism would improve intergroup relations more than would colorblindness was greater among Black than White participants. Simple effects tests further indicated that in both studies Blacks endorsed multiculturalism more than colorblindness and Whites endorsed colorblindness more than did Blacks. Although, as expected, Blacks exhibited stronger ethnic identities and reported greater intergroup experiences than did Whites, ethnic group differences in ideologies remained when these differences were controlled. Thus, our measures of multicultural and colorblind approaches to improving intergroup relations clearly assess something more than the importance of ethnic identity to oneself (i.e. ethnic identity) and interest in or experience with other ethnic groups (i.e. intergroup experiences).

Also, as expected, the relationship between ideology and stereotype strength differed for Blacks and Whites. Blacks who more strongly endorsed a multicultural relative to a colorblind ideology exhibited stronger stereotypes. This relationship was evident in both studies, using three measures of stereotype strength. Although the relationship for Whites consistently differed from that for Blacks, the relationship for Whites was less consistent. In Study 1, Whites who more strongly endorsed a colorblind relative to a multicultural ideology exhibited stronger stereotypes. In Study 2, the same relationship was evident in judgments of dispersion, but not in judgments of stereotypicality.

Previous experimental research among White participants has demonstrated that multiculturalism (vs. colorblindness) also results in lower ethnocentrism on both explicit and implicit measures of prejudice (Richeson \& Nussbaum, 2004). The present results further demonstrated this relationship among Blacks and Whites who were asked whether they personally believed that multicultural and colorblind ideologies would improve intergroup relations. However, the relationship was evident only in Study 2. Although we cannot be sure, the lack of a relationship in Study 1 seems likely to have resulted from the small and unique sample. In any case, the pattern of results across studies suggests that multiculturalism is associated with less ethnocentrism.

Although strong social norms against stereotyping and prevailing beliefs that stereotypes are inherently racist are likely to prevent Whites from expressing stronger stereotypes, social desirability seems an unlikely explanation for the present findings. First, as noted above, White participants who more strongly endorsed a colorblind relative to multicultural ideology actually exhibited stronger stereotypes on two of the three measures of stereotype strength. Second, the effects were evident among Blacks and Whites who voluntarily participated in a diversity program and who exhibited ethnocentrism and out-group homogeneity on explicit measures. Third, stronger endorsement of a multicultural relative to a colorblind ideology was associated with greater internal motivation to control prejudice, which is inconsistent with a social desirability explanation, but quite consistent with the argument that a colorblind ideology may serve to justify the status quo (Barrett \& George, 2005; Flagg, 1993; Gotanda, 1995).

Of course, people's beliefs about how to improve intergroup relations-however genuine and well-intended they may be-do not necessarily translate into the sorts of specific attitudes and behaviors that actually promote intergroup 
harmony. A great deal of research indicates that stereotyping, prejudice, and discrimination continue despite strong social norms against them (Fazio et al., 1995; McConnell \& Leibold, 2001). Further, the positive relationship between colorblindness and stereotypes among Whites suggests that people sometimes deceive themselves about their ability to ignore ethnicity (Norton et al., 2006). And multiculturalism, with its focus on group differences and positive association with stereotype strength, may inadvertently promote an inappropriate use of stereotypes. The important point is that Blacks and Whites appear to hold different ideological views regarding ways to improve intergroup relations and these diverging views may result in misunderstandings and conflict. The debate regarding affirmative action is a case in point. Affirmative action policies require people to take into account ethnic group membership, which seems difficult to reconcile with a strong colorblind ideology. Indeed, recent data from the National Election Studies for the year 2000 (Krysan, 2002) are consistent with the present findings. These data indicate that the vast majority of White Americans (92\%) oppose affirmative action in hiring and promotion, whereas Black Americans (67\%) generally, but less uniformly, favor it.

We wish to emphasize, however, that we do not believe that multicultural and colorblind ideologies are necessarily conflicting. Indeed, the present data revealed a positive correlation between the two among both Blacks and Whites, suggesting that our participants also do not consider the two ideologies as necessarily conflicting. Acknowledging and celebrating the distinctive aspects of people's ethnic heritage in some situations, for example, celebrating Juneteenth in the Black community, is not incompatible with attempting to ignore group membership in other situations that do not call for a focus on ethnicity, for example, seating and serving people in restaurants and other public accommodations (although even these situations may sometimes call for a multicultural approach as when non-native persons behave in ways that are appropriate in their homelands but violate local customs). In addition to social policy issues, then, an important avenue for future research is to identify the consequences of multiculturalism and colorblindness for particular intergroup situations. This issue has only recently begun to be addressed. Norton et al. (2006), for example, demonstrated that Whites were more likely to avoid mentioning race when interacting with a Black confederate, which resulted in less efficient performance on a task in which race information was relevant and in less friendly nonverbal behaviors (e.g. less eye contact) toward their Black partners. Norton et al. concluded that adopting a colorblind approach may be ineffective and even backfire in circumstances that clearly call for the explicit recognition of ethnicity.

In addition, a desire to improve intergroup harmony may not be the only or even primary purpose of endorsing multicultural and colorblindness ideologies. As we noted in the introduction, both ideologies also concern what is perceived to be fair and just-regardless of their consequences for intergroup harmony. Endorsement of one ideology relative to another may well depend on the desired outcome. In any case, the assumption that all people are the same needs to be tempered by an appreciation of the ways in which groups of people may differ in meaningful ways (cf. Brown \& Hewstone, 2005).

Other findings from the present studies are also noteworthy. Black participants exhibited stronger stereotypes as well as ethnocentrism in both studies. White participants exhibited the classic ethnocentrism effect in Study 1 on the feeling thermometer task. These results are consistent with those of Judd et al. (1995) who argued that differences in stereotype strength and ethnocentrism result from different socialization experiences for Blacks and Whites. Blacks are socialized to accept and embrace their ethnic heritage, whereas Whites are socialized to believe that it is simply wrong to acknowledge ethnic group differences. The present findings are thus supportive of the Judd et al. findings and theoretical analysis. Contrary to their research, however, both of the present studies also revealed 
out-group homogeneity-both Blacks and Whites perceived the out-group to be less variable than the in-group. In addition to providing evidence of the out-group homogeneity effect with ethnic groups, the present research underscores the importance of replicating findings across diverse samples.

Our measure of intergroup experiences also yielded several interesting findings. Participants who had more intergroup experiences were less likely to endorse multiculturalism relative to colorblindness as a means for improving intergroup relations, perceived the groups as less stereotypic, and exhibited less ethnocentrism. The latter findings are consistent with the contact hypothesis (Allport, 1954) in which greater contact with an out-group is generally associated with less prejudice (Brown \& Hewstone, 2005; Pettigrew \& Tropp, 2006). We can only speculate on the negative relation between intergroup experiences and multiculturalism versus colorblindness. However, it seems reasonable that people who have greater contact perceive ethnic group differences as less important than their common identity (Eller \& Abrams, 2003, 2004; Gaertner \& Dovidio, 2000).

Additional research examining intergroup relations issues from the perspective of minority group members is sorely needed (cf. Shelton, 2000). Empirical research is increasingly documenting qualitative differences in minority and majority group members' experiences and beliefs. Monteith and Spicer (2000), for example, found that White participants' racial attitudes stemmed from egalitarianism, whereas Black participants' racial attitudes appeared to be rooted in reactions to perceived prejudice and discrimination. Similarly, although both minority group members and dominant group members experience anxiety during intergroup encounters, the level and quality of anxiety appear to differ. Minority group members are mindful of protecting themselves, whereas dominant group members are mindful of the novelty of the encounter (Frable, Blackstone, \& Scherbaum, 1990; Hyers \& Swim, 1998). Thus, even when Blacks and Whites exhibit the same attitudes or behaviors, the processes that underlie them may differ as a result of differing social, economic, political, and historical experiences. If we are to fully understand human behavior and, ultimately, improve relations among ethnic groups, it seems important to identify both the similarities and differences among them.

\section{Notes}

1. Analyses in which intergroup familiarity and ethnic identity were controlled yielded the same conclusions.

2. Analyses in which multicultural and colorblind ideology were included as separate continuous (centered) predictors as well as analyses including the interaction between the two predictors yielded weak and inconsistent results. None of the multicultural $\times$ colorblind interactions was significant.

3. Note that perceiving greater intragroup similarity in both target groups does not necessarily reflect a lack of intergroup differentiation. That is, participants may have viewed Blacks as highly similar to each other and Whites as highly similar to each other, but at opposite ends of stereotype-relevant dimensions. Consider, for example, the dimension not spoiled-spoiled. Blacks may be perceived as low on this dimension and Whites may be perceived as high as the attribute 'spoiled' is considered counterstereotypic of Blacks and stereotypic of Whites (Study 2). To the extent that participants perceive high intragroup similarity in both groups, their stereotypes would be considered strong and intergroup differentiation would be high.

4. Additional analyses, one including ethnicity and one in which parameters were estimated separately for Blacks and Whites, indicated that the structure of the data was the same for both Blacks and Whites.

5. In the mixed model analysis of covariance, the target group $\times$ participant group $\times$ attribute valence $\times$ ideology interaction tests the relationship between ideology and ethnocentrism. The test of the coefficient associated with ideology in the regression analysis provides an equivalent test of this relationship. The regression analysis also provided a test of the interaction between ideology and participant group. 


\section{Acknowledgements}

This research was supported by National Institute of Mental Health Grant R01 MH62061. We thank Janet Schofield, Ana Guinote, and the participants of the EAESP Small Group Conference on the Psychology of Minorities for helpful comments concerning this research; Martha Florence and Michelle Kosmicki for the data for Study 1; Eva Denton, Koichi Kurebayshi, and Molly Wernli for help with collecting and coding data; and April Seifert for help with data analyses.

\section{References}

Allport, G. W. (1954). The nature of prejudice.

New York: Addison-Wesley.

Barrett, K. H., \& George, W. H. (2005). Judicial colorblindness, race neutrality, and modern racism: How psychologists can help the courts understand race matters. In K. H. Barrett \& W. H. George (Eds.), Race, culture, psychology and law (pp. 31-46). Thousand Oaks, CA: Sage.

Berry, J. W. (1999). Intercultural relations in plural societies. Canadian Psychology, 40, 12-21.

Berry, J. W., \& Kalin, R. (1995). Multicultural and ethnic attitudes in Canada: An overview of the 1991 national survey. Canadian Journal of Behavioural Science, 27, 301-320.

Brauer, M. (2001). Intergroup perception in the social context: The effects of social status and group membership on perceived out-group homogeneity and ethnocentrism. Journal of Experimental Social Psychology, 37, 15-31.

Brewer, M. B. (1993). Social identity, distinctiveness, and in-group homogeneity. Social Cognition, 11, 150-164.

Brown, R., \& Hewstone, M. (2005). An integrative theory of intergroup contact. In M. P. Zanna (Ed.), Advances in experimental social psychology (Vol. 37, pp. 255-343). San Diego, CA: Elsevier Academic Press.

Caughy, M. O., O'Campo, P. J., Randolph, S. M., $\&$ Nickerson, K. (2002). The influence of racial socialization practices on the cognitive and behavioral competence of African American preschoolers. Child Development, 73, 1611-1625.

Eller, A., \& Abrams, D. (2003). Gringos in Mexico: Cross-sectional and longitudinal effects of language school-promoted contact on intergroup bias. Group Processes $\mathcal{E}$ Intergroup Relations, 6, 55-75.

Eller, A., \& Abrams, D. (2004). Come together: Longitudinal comparison of Pettigrew's reformulated intergroup contact model and the Common Ingroup Identity Model in Anglo-French and Mexican-American contexts. European Journal of Social Psychology, 34, 229-256.

Fazio, R. H., Jackson, J. R., \& Dunton, B. C. (1995). Variability in automatic activation as an unobtrusive measure of racial attitudes: A bona fide pipeline? Journal of Personality and Social Psychology, 69, 1013-1027.

Flagg, B.J. (1993). 'Was blind, but now I see': White race consciousness and the requirement of discriminatory intent. Michigan Law Review, 91, 953-1017.

Frable, D. E. S., Blackstone, T., \& Scherbaum, C. (1990). Marginal and mindful: Deviants in social interactions. Journal of Personality and Social Psychology, 59, 140-149.

Gaertner, S. L., \& Dovidio, J. F. (1986). The aversive form of racism. In J.F. Dovidio \& S.L. Gaertner (Eds.), Prejudice, discrimination, and racism (pp. 61-89). Orlando, FL: Academic Press.

Gaertner, S. L., \& Dovidio, J. F. (2000). Reducing intergroup bias: The Common Ingroup Identity Model. Philadelphia, PA: Psychology Press.

Gotanda, N. (1995). A critique of 'our constitution is color-blind'. In K. Crenshaw, N. Gotanda, G. Peller, \& K. Thomas (Eds.), Critical race theory: The key writings that formed the movement (pp. 257-275). New York: The New Press.

Harrison, A. O., Wilson, M. N., Pine, C. J., Chan, S. Q., \& Buriel, R. (1990). Family ecologies of ethnic minority children. Child Development, 61, 347-362.

Hu, L., \& Bentler, P.M. (1999). Cutoff criteria for fit indexes in covariance structure analysis: Conventional criteria versus new alternatives. Structural Equation Modeling, 6, 1-55.

Hyers, L. L., \& Swim, J. K. (1998). A comparison of the experiences of dominant and minority group members during an intergroup encounter. Group Processes and Intergroup Relations, 1, 143-163.

Ito, T. A., \& Urland, G. R. (2003). Race and gender on the brain: Electrocortical measures of attention to the race and gender of multiply categorizable individuals. Journal of Personality and Social Psychology, 85, 616-626.

Judd, C. M., Park, B., Ryan, C. S., Brauer, M., \& Kraus, S. (1995). Stereotypes and ethnocentrism: Diverging interethnic perceptions of African American and White American youth. Journal of Personality and Social Psychology, 69, 460-481.

Krysan, M. (2002). Data update to Racial attitudes in America. An update and website to complement H. Schuman, C. Steeh, L. Bobo, \& M. Krysan, 
(1997). Racial attitudes in America: Trends and interpretations (rev. ed.). Cambridge, MA: Harvard University Press. http:/ / tigger.uic. edu/ krysan/racialattitudes.htm.

Lee, Y., Jussim, L. J., \& McCauley, C. R. (Eds.) (1995). Stereotype accuracy: Toward appreciating group differences. Washington, DC: American Psychological Association.

Markus, H. R., Steele, C. M., \& Steele, D. M. (2002). Color blindness as a barrier to inclusion: Assimilation and nonimmigrant minorities. In R. Schweder, M. Minow, \& H. R. Markus (Eds.), Engaging cultural differences: The multicultural challenge in liberal democracies (pp. 453-472). New York: Russell Sage Foundation.

McConnell, A. R., \& Leibold, J. M. (2001). Relations among the Implicit Association Test, discriminatory behavior, and explicit measures of racial attitudes. Journal of Experimental Social Psychology, 37, 435-442.

Monteith, M. J., \& Spicer, C. V. (2000). Contents and correlates of Whites' and Blacks' racial attitudes. Journal of Experimental Social Psychology, 36, 125-154.

Mullen, B., Brown, R., \& Smith, C. (1992). Ingroup bias as a function of salience, relevance, and status: An integration. European Journal of Social Psychology, 22, 103-122.

Norton, M. I., Sommers, S. R., Apfelbaum, N. P., Pura, N. \& Ariely, D. (2006). Color blindness and interracial interaction: Playing the political correctness game. Psychological Science, 17, 949-953.

Park, B., \& Judd, C. M. (2005). Rethinking the link between categorization and prejudice within the social cognition perspective. Personality and Social Psychology Review, 9, 108-130.

Park, B., Judd, C. M., \& Ryan, C. S. (1991). Social categorization and the representation of variability information. In W. Stroebe \& M. Hewstone (Eds.), European Review of Social Psychology (Vol. 2, pp. 211-245). Chichester, UK: Wiley.

Park, B., \& Rothbart, M. (1982). Perception of out-group homogeneity and levels of social categorization: Memory for the subordinate attributes of in-group and out-group members. Journal of Personality and Social Psychology, 63, 1051-1068.

Pettigrew, T. F., \& Tropp, L. R. (2006). A metaanalytic test of intergroup contact theory. Journal of Personality and Social Psychology, 90, 751-783.

Phinney, J. S. (1992). The multigroup ethnic identity measure: A new scale for use with diverse groups. Journal of Adolescent Research, 7, 156-176.

Plant, E. A., \& Devine, P. G. (1998). Internal and external motivation to respond without prejudice. Journal of Personality and Social Psychology, 75, 811-832.

Ramirez, M. (1998). Multicultural/multiracial psychology: Mestizo perspectives in personality and mental health. Northvale, NJ: Jason Aronson.

Richeson, J. A., \& Nussbaum, R. J. (2004). The impact of multiculturalism versus colorblindness on racial bias. Journal of Experimental Social Psychology, 40, 417-423.

Ryan, C. S. (1996). Accuracy of black and white college students' in-group and out-group stereotypes. Personality and Social Psychology Bulletin, 22, 1114-1127.

Ryan, C. S. (2002). Stereotype accuracy. In W. Stroebe \& M. Hewstone (Eds.), European Review of Social Psychology (vol. 13, pp. 75-109). Hove, UK: Psychology Press.

Satorra, A., \& Bentler, P.M. (1994). Corrections to test statistics and standard errors in covariance structure analysis. In A. von Eye \& C.C. Clogg (Eds.), Latent variables analysis: Applications for developmental research (pp. 399-419). Thousand Oaks, CA: Sage.

Satorra, A., \& Bentler, P.M. (2001). A scaled difference chi-square test statistic for moment structure analysis. Psychometrika, 66, 507-514.

Schofield, J. W. (2001). The colorblind perspective in school: Causes and consequences. In J. A. Banks \& C. A. McGee (Eds.), Multicultural education: Issues and perspectives (4th ed., pp. 247-267). New York: Wiley.

Sellers, R. M., \& Shelton, J. N. (2003). The role of racial identity in perceived racial discrimination. Journal of Personality and Social Psychology, 84, 1079-1092.

Shelton, J. N. (2000). A reconceptualization of how we study issues of racial prejudice. Personality and Social Psychology Review, 4, 374-390.

Simon, B., \& Pettigrew, T. F. (1990). Social identity and perceived group homogeneity: Evidence for the in-group homogeneity effect. European Journal of Social Psychology, 20, 269-286.

Swim, J.K., \& Miller, D.L. (1999). White guilt: Its antecedents and consequences for attitudes toward affirmative action. Personality and Social Psychology Bulletin, 25, 500-514.

Thornton, M. C. (1997). Strategies of racial socialization among Black parents: Mainstream, minority, and cultural messages. In R. J. Taylor, J. S. Jackson, \& L. M. Chatters (Eds.), Family life 
in Black America (pp. 210-215). Thousand Oaks, CA: Sage.

Verkuyten, M. (2005). Ethnic group identification and group evaluation among minority and majority groups: Testing the multiculturalism hypothesis. Journal of Personality and Social Psychology, 88, 121-138.

Verkuyten, M. (2006). Multicultural recognition and ethnic minority rights: A social identity perspective. In W. Stroebe \& M. Hewstone (Eds.), European Review of Social Psychology (Vol. 17, pp. 148-184). Hove, UK: Psychology Press.

Wolsko, C., Park, B., Judd, C. M., \& Wittenbrink, B. (2000). Framing interethnic ideology: Effects of multicultural and colorblind perspectives on judgments of groups and individuals. Journal of Personality and Social Psychology, 78, 635-654.

Paper received 31 July 2006; revised version accepted 9 July 2007

\section{Biographical Notes}

CAREY S. RYAN is a professor of psychology at the University of Nebraska at Omaha. Her research interests include stereotyping and prejudice, stereotype accuracy, group processes, and diversity issues in organizations.

JENNIFER S. HUNT is an associate professor of psychology at Buffalo State College in New York. Her research interests include stereotyping and discrimination, eyewitness behavior, and gender and race issues.

JOSHUA A. WEIBLE received his MA in Industrial/ Organizational Psychology from the University of Nebraska at Omaha and is now employed in the private sector.

CHARLES R. PETERSON received his MA in Industrial/Organizational Psychology from the University of Nebraska at Omaha and is now employed in the private sector.

JUAN F. CASAS is an associate professor of psychology at the University of Nebraska at Omaha. His research interests include relational aggression, victimization, and peer relationships among children as well as issues concerning Latino children and families in the US. 